\title{
Co-authors, colleagues, and contributors: Complexities in collaboration and sharing lessons on academic writing
}

Orlanda Harvey ${ }^{1 \star}$, Alexander van Teijlingen ${ }^{2}$, Pramod R. Regmi ${ }^{1,3,4}$, Jillian Ireland ${ }^{1,5}$, Aney Rijal ${ }^{6}$, Edwin R. van Teijlingen ${ }^{1,7,8}$

${ }^{1}$ Faculty of Health and Social Sciences, Bournemouth University, UK

${ }^{2}$ Department of Pure and Applied Chemistry, University of Strathclyde, UK

${ }^{3}$ Visiting Fellow, Chitwan Medical College, Nepal

${ }^{4}$ Visiting Fellow, Datta Meghe Institute of Medical Sciences, India

${ }^{5}$ University Hospitals Dorset NHS Foundation Trust, Dorset, UK

${ }^{6}$ Executive Editor, Health Prospect, Maharajgunj, Kathmandu, Nepal

${ }^{7}$ Visiting Professor, Manmohan Memorial Institute of Health Sciences, Nepal

${ }^{8}$ Visiting Professor, Nobel College, Nepal

Received:

23 August 2021

Revised:

3 December 2021

Accepted:

6 December 2021

${ }^{*}$ Corresponding author

harveyo@bournemouth. ac.uk

DOI: $10.3126 /$ hprospect.

v21i1.39320

\begin{abstract}
Academic writing, especially in the health field, is usually an interdisciplinary team effort. This paper highlights some of the trials, tribulations, and benefits of working with co-authors. This includes collaborations and co-authorship between academics from different disciplines, academics of different level of careers, and authors from countries of varying economies i.e., high-income countries (HICs) and from low-and middle-income countries (LMICs). This paper also provides advice in the form of several useful tips to lead authors and co-authors to support collaborative working.
\end{abstract}

Keywords: Academic writing, collaboration, interdisciplinary approach, co-authorships

Tweetable abstract: Frank discussions and clear agreements is required during writing process and authorship order.

\section{Introduction}

A lot has been written about academic publishing as well as authors' writing styles. However, less has been published about the actual collaborative writing processes. Some of it appears in papers about interdisciplinary working, bringing together authors from a variety of disciplines and often with different perspectives and preferred methods.

Working with fellow academics is often compared to herding cats, the typical academic is intelligent, independent, and perhaps, opinionated [1]. Bringing a group of clever people together to fulfil one task can lead to great creative solutions along with producing scientific knowledge in limited resources but also difficult working relationships. At present, the increased use of computers, mobile devices, social media, professional networking platforms have enabled collaborative academic writing across the globe more than ever before [2]. As with all teamwork, individuals generally have different ways of working and may have contrasting writing styles. In a team of authors some of these ways of working as well as some of these styles of writing might clash. This is on the top of differences in perspectives, personalities, and disciplinary backgrounds. For example, the authors of this paper have their disciplinary backgrounds in chemistry, international health, education, social work, midwifery, sociology, and public health.

There is the potential for greater conflict within diverse writing teams which are operating increasingly online/virtual when compared to teams with more similar related backgrounds. The more diverse the team the greater the chance of having heterogeneous communication styles and ways of working; however, this can also lead to greater levels of creativity and better problem-solving [3]. To overcome this challenge, DuFrene and Lehman advocate for establishing clear communication, setting out clear roles and responsibilities, and a level of accountability [3]. The latter is another potential challenge when collaborating on a paper with a group of peers, working with colleagues who are equals often means there is little or no traditional forms of accountability. Hence trust being very important, as a failure of trust within diverse teams can lead to a failed collaboration and papers/manuscripts not being completed [4]. Therefore, a key to effective teamwork is the building of trust, where team members need to reach or demonstrate a point where they are transparent and honest with each other [5].

Working with your peers, i.e., people who are your equal, should not result in the absence of leadership. Someone needs to take a lead role in manage a writing team, in other words, it is important to have an effective leadership [6]. Leadership is an interesting challenge in academic teams existing of clever people who do not necessarily wish to be led [7]. 
In any collaborative team there can be both interprofessional and personal conflicts including time management, scheduling problems and an imbalance in the distribution of tasks between co-authors [8]. However, Rice and colleagues also suggested there are several distinct advantages namely: the enhancement of personal relationships and mutual perspectives and greater productivity [8]. Moreover, as Senge noted nearly two decades ago, the collective dialogue deepens relationships, creates alignment, and enables new realities [9].

Often, but not always, it is the first author who assumes the leadership role [10]. The first author is likely to prepare the skeleton of the paper or even first draft. The leader needs to help build trust within the team, support a clear flow of information between co-authors, set a clear goal (e.g., collaborating on a research findings paper to be submitted to specified journal), define individual authors' roles and responsibilities, and resolve any conflicts and appreciate individual differences [11].

\section{Common challenges}

This section sets out several typical conflicts that can occur within writing teams. Everybody who has worked on a few collaborative papers will recognise many of the barriers and obstacles in working with co-authors.

One typical issue is co-authors not delivering their contribution, either not producing anything at all or by being late. Reasons for this might include co-authors being: (a) too busy; (b) away from their usual workplace; (c) in lockdown, and (d) in rural areas out of reach of internet and/or poor WIFI connectivity. Co-authors who contribute late represent perhaps a more delicate problem, especially if these coauthors are key to the completion of the paper. Co-authors could be genuinely very busy, with marking students' work, grant applications, in their family life or due to conditions related to personal health and wellbeing. You may feel it to be understandable, but the reality is that they are holding up the progress of your paper.

Another common issue that may appear when co-authoring is to find a suitable method for reviewing, editing, and adding comments to a draft paper. Some of your colleagues may be familiar with and have access to online document repositories (e.g., shared drive, Teams) that allow for co-commenting, whereas others may reply on numerous versions being sent via email. It is advisable to make sure each co-author uses the tracked changes option, regardless of the format you use to share a draft paper, be it an email attachment or an online link to a joint document on, for example, Google Docs, Dropbox, Moxtra, Box, or OneDrive. Without tracked changes it would be very difficult for the lead author to follow who changed what in the draft.

Regardless of the medium used, co-authors may also produce material that is not very useful, perhaps their input is unfocused or irrelevant. For example, they might be providing you with vague and general advice such as 'rewrite/rephrase/add more detail without doing this themselves or offering just bullet point with ideas. Or often equally poor, giving no advice and saying things like: "It's all fine as it stands". In addition, some co-authors may offer unrealistic editing and add or change text in an impossible way.

Occasionally, you'll find that your co-author has changed major aspects or sense of the draft. Co-authors may also suggest to the rest of the team more research, which is unhelpful when the paper is already based on plenty of data. In a multi-disciplinary team, but not just there, you may find yourself seeing the world differently than your co-authors. You might notice this is in the editing process when you get a draft back and find the co-author has edited the paper so thoroughly that it changed the nature of the paper completely. In a similar vein, you may find that a co-author has changed the Discussion and Conclusion sections not on the basis of the paper but on the basis of an argument they had at a conference last week. When you are working with academics who are also practitioners, for example a health or social care professional you may find that they have added recommendations for practice in the paper's Conclusion section that are not necessarily fully supported by the data, or worse than that they have changed your academic discussion to a much more practice-based discussion section or vice versa.

In defence of co-authors, it can be challenging to meet the demands of their busy workload and find the necessary time to contribute as a co-author of the paper. Remember that some co-authors may have committed to jointly writing a paper a long time ago, for example the grant application could have been written years before the data become available for analysis and writing up. Even if you have drawn up a writing plan at the start of the study, collaborators' work and home live may have changed considerably. It is sometimes difficult to know what to do, this is especially true if the first author fails to give clear guidance or if the first author does not give clear permission what can be changed (and what should not be changed). Table 1 outlines a number of questions which co-authors may face.

\section{Table 1: Potentially confusing issues for co-authors}

- How can you rewrite a draft if you don't understand what you are meant to do?

- How can you comment consistently if the first and the second authors are changing each other's arguments in each round of editing?

- How can you meet publication deadlines when your work may depend on another's deadline that has not been met?

- Should you comment on the whole paper or focus aspects of the paper that link to your own area of expertise? The latter might be the clinical discipline, statistics, ethics, mixed-methods research, sociology, lab-based science, or health economics.

- How can you challenge colleagues if you see them as more senior than you or having more authority than you?

- If the first author gives vague instructions such as: 'Edit as you see fit' or more generally: 'Please edit this draft' then the co-authors may wonder what exactly is expected of them.

There are further challenges if there is a clear power imbalance or seniority/experience difference between colleagues. When co-authors are also the first author's supervisor, they can be a bit more reluctant to do too much writing of the student's paper especially if it is early 
in the $\mathrm{PhD}$ process. The supervisor does not want (to be seen) to be doing the writing for the postgraduate student. Moreover, there is an element of learning for the postgraduate student since "many students (and academics) do not realise that writing a scientific paper for publication is different from writing a $\mathrm{PhD}$ chapter" [12]. There can be the reversal of this too where the student feels unable to challenge the wisdom of their supervisor.

\section{Some advice to improve working with your co-author}

In our view many problems can be avoided with frank discussions and clear agreements about the writing process, and about authorship order. Sort out early who is going to be first author. Another practical issue to consider is the barriers created by the constrains set by your target journal. Select your journal early in the writing process, not only for the maximum number of authors allowed, but also to use the appropriate writing style, maximum number of figures, maximum word count etc., such that every co-author is more likely to be working towards the same goal. Regardless of the way of working between co-authors, one person, usually the lead author or corresponding author should have the overall responsibility for editing, submitting, etc. [8]. Co-authors could be asked to commit to an agreement at the outset and follow it throughout the writing period; this could be facilitated by the first author, and then referred back to as needed.

When working in a global team remember that collaborators from LMIC (low-and middle-income countries) are often underrepresented in academic publications, for example due to language issues [13]. Some LMIC collaborators are not going to be able to contribute directly to the editing sections of text in English language. One solution you may like to consider is for one co-author who speaks the collaborator's native language to act as translator and scribe their ideas during the paper writing process.

When there are problems requiring a meeting of the team make sure that the agreed solution is clearly summarised and recorded and do this as early as possible. It is worthwhile to track co-authors' contributions to the paper throughout a project particularly if it is a long one with lots of experiments, field work or analysis. More precisely, we suggest:

1. The lead author (or authors) needs to set realistic deadlines for each collaborator.

2. Make it clear to each co-author who should write which part of the paper.

3. Make it clear who should edit first and who should go after that.

4. Ensure that co-authors are set tasks according to their contribution to the research, their individual strengths, and their level of experience. For example, don't ask the qualitative researcher to write up the statistics.

5. Put documents on a shared drive so different co-authors can work at the same time.

6. Remind co-authors a few days before the deadline that their contribution is expected in, for example, ten days' time, or by the end of the week or the beginning of next month.

7. Take time zones and cultural calendars into consideration. Next to nobody in the western world would dream of setting a deadline of 25th of December, however many researchers may not know, or be mindful of the dates of Eid al-Fitr, Diwali, Nepali New Year, etc. There is no excuse for this in today's world, with such ease of access to this information via the internet. Lead researchers should try to be mindful of this when engaging in international collaboration.

8. Time zone synchronization, particularly when inter-continental, generally online meetings should be scheduled during the working day for all involved, where this is not possible, e.g., USA - UK - Nepal collaboration a reasonable concession should be made from all parties.

9. Set clear tasks, for example state clearly: "read and rewrite the Conclusion, but don't change anything major in the Methods section".

10. Have explicit conversations about authorship and authorship order early on with all team members.

11. Recognise individual contribution and adjust the authorship order when one particular co-author has done more than expected or considerably less than expected.

12. If you are the co-author, try to complete your tasks as asked by the lead author. If you can't make the deadline let them know, perhaps ask for more time or ask for another co-author to go first. You may also suggest a change in author order and put your name further down the list of authors.

13. Be honest and fair, and if your other commitments have changed and you can no longer find the space to contribute, ask for your name to be removed.

14. Consider your own way of working and writing style, once you have understood this you can communicate this to your coauthors.

15. Consider how your co-authors work and write. Discuss any differences of styles openly and perhaps adapt to the styles of others if this is required maintain harmonious working.

\section{Competing interest}

Aney Rijal and Pramod Regmi are on the editorial board of Health Prospect. The other co-authors declare that they have no competing interests.

\section{References}

1. Erez, M, Shneorson, Z. Personality types and motivational characteristics of academics versus professionals in industry in the same occupational discipline J Vocational Behav, 1980;17(1): 95-105 https://doi.org/10.1016/0001-8791(80)90019-6 
2. Green BN, Johnson CD. Interprofessional collaboration in research, education, and clinical practice: Working together for a better future. J Chiropr Educ. 2015;29:1-10. doi: 10.7899/JCE-14-36.

3. DuFrene, DD, Lehman CM. Managing Virtual Teams (2nd Edn.), New York: Business Expert Press, 2016.

4. Gratton, L, Voigt, A, Erickson, T. Bridging faultlines in diverse teams, IEEE Eng Manag Rev, 2011;39(1): 80-90 DOI:10.1109/EMR.2011.5729976

5. Lencioni, P. Building a Healthy Organization, School Adm, 2013;70(2): 39-43.

6. Tshetshema, CT, Chan, KY. A systematic literature review of the relationship between demographic diversity and innovation performance at team-level, Techno Anal Strateg Manag. 2020;32(8): 955-967, DOI: 10.1080/09537325.2020.1730783

7. Goffee, R, Jones, G. Leading Clever People, Harv Bus Rev. 2007;85(3):72-9. https://hbr.org/2007/03/leading-clever-people .

8. Hundley, V, van Teijlingen, E, Simkhada, P. Academic authorship: who, why \& in what order? Health Renaiss 2013;11(2): 98-101 www.healthrenaissance.org.np/ uploads/Download/vol-11-2/Page_99_101_Editorial.pdf

9. Turaga, R. Building Trust in Teams: A Leader's Role. IUP J Soft Skills, 2013;7(2):13-31.

10. Rice, RP., Huguley, JT. Describing collaborative forms: a profile of the team-writing process, IEEE Trans Prof Commun, 1994;37(3): 163-170. DOI $10.1109 / 47.317482$

11. Senge, P. Creating communities. Exec Excell. 2004;21(9): 4-5.

12. Kohrt, BA., Upadhaya, N, Luitel, NP, Maharjan, SM, Kaiser, BN, MacFarlane, EK, Khan, N. Authorship in Global Mental Health Research: Recommendations for Collaborative Approaches to Writing and Publishing. Ann Glob Health. 2014;80(2):134-142. http://doi.org/10.1016/j.aogh.2014.04.007

13. Regmi, P, Poobalan, A, Simkhada, P, van Teijlingen, E. PhD supervision in Public Health. Health Prospect. 2021;20(1):1-4. https://doi.org/10.3126/hprospect. v20i1.32735 